\title{
Open access to regional geoid models: the International Service for the Geoid
}

\author{
Mirko Reguzzoni ${ }^{1}$, Daniela Carrion ${ }^{1}$, Carlo Iapige De Gaetani ${ }^{1}$, Alberta Albertella ${ }^{1}$, Lorenzo Rossi ${ }^{1}$, \\ Giovanna Sona $^{1}$, Khulan Batsukh ${ }^{1}$, Juan Fernando Toro Herrera ${ }^{1}$, Kirsten Elger ${ }^{2}$, Riccardo Barzaghi ${ }^{1}$, \\ and Fernando Sansó ${ }^{1}$ \\ ${ }^{1}$ International Service for the Geoid, Department of Civil and Environmental Engineering, \\ Politecnico di Milano, Milan, 20133, Italy \\ ${ }^{2}$ GFZ German Research Centre for Geosciences, Telegrafenberg, 14473 Potsdam, Germany \\ Correspondence: Carlo Iapige De Gaetani (isg@polimi.it)
}

Received: 17 December 2020 - Discussion started: 23 December 2020

Revised: 3 March 2021 - Accepted: 4 March 2021 - Published: 21 April 2021

\begin{abstract}
The International Service for the Geoid (ISG, https://www.isgeoid.polimi.it/, last access: 31 March 2021) provides free access to a dedicated and comprehensive repository of geoid models through its website. In the archive, both the latest releases of the most important and well-known geoid models, as well as less recent or less known ones, are freely available, giving to the users a wide range of possible applications to perform analyses on the evolution of the geoid computation research field. The ISG is an official service of the International Association of Geodesy (IAG), under the umbrella of the International Gravity Field Service (IGFS). Its main tasks are collecting, analysing, and redistributing local, regional, and continental geoid models and providing technical support to people involved in geoid-related topics for both educational and research purposes. In the framework of its activities, the ISG performs research taking advantage of its archive and organizes seminars and specific training courses on geoid determination, supporting students and researchers in geodesy as well as distributing training material on the use of the most common algorithms for geoid estimation. This paper aims at describing the data and services, including the newly implemented DOI Service for geoid models (https://dataservices.gfz-potsdam.de/portal/?fq=subject:isg, last access: 31 March 2021), and showing the added value of the ISG archive of geoid models for the scientific community and technicians, like engineers and surveyors (https://www.isgeoid.polimi.it/Geoid/reg_list.html, last access: 31 March 2021).
\end{abstract}

\section{Introduction}

The geoid, an equipotential surface of the Earth gravity field (Heiskanen and Moritz, 1967; Sansò and Sideris, 2013), has important applications in engineering for the definition of physical heights (Sansò et al., 2019), for example to compute them from ellipsoidal heights observed by Global Navigation Satellite System (GNSS) techniques, and in geosciences, for example to determine the ocean geostrophic currents (Bingham et al., 2008; Knudsen et al., 2011). Because of its definition, the geoid is naturally modelled as a surface at a global level, typically through a truncated spherical harmonic expansion. The use of base functions on a spherical domain is justified by the fact that the geoid undulation is an anomalous quantity with respect to a given reference ellipsoid, while the truncation of the series expansion depends on the spatial resolution of the model. For example, a maximum spherical harmonic degree of 360 means an angular resolution of about $30 \mathrm{arcmin}$. The coefficients of this spherical harmonic expansion, representing a global geopotential model, have been estimated since the middle of the last century, especially exploiting satellite techniques (Merson and King-Hele, 1958; Barzaghi et al., 2015a), such as satellite orbit tracking and radar altimetry. With the advent of the new century, dedicated satellite gravity missions, i.e. CHAMP, GRACE, and GOCE, were launched, significantly improving the knowledge of the gravity field. In this framework, the need for 
open-access global models estimated by different research groups with different techniques led to the establishment of the International Centre for Global Earth Models (ICGEM) (Ince et al., 2019), an official International Association of Geodesy (IAG) service with the aim of distributing global models and also providing computational and visualization online tools.

However, global models from dedicated satellite missions are limited in terms of spatial resolution due to the dampening of the gravity signal with the orbital height (Pail et al., $2010,2011)$. The use of ground gravity data allows an increase in the global model spatial resolution, but, as a consequence of the inhomogeneous spatial distribution of these data (Pavlis et al., 2012), a certain level of regularization is required to compute the coefficients of global base functions. This regularization can also affect the quality of the geoid estimation in areas where data spatial density is higher. For these reasons, and also for historical reasons related to the way in which the heights and the gravity data were observed, each country usually has its own geoid model. Biases are typically present between geoids of neighbouring countries, accounting for the different used conventions, e.g. the different reference tide gauge (Rummel and Teunissen, 1988; Sansò and Usai, 1995; Barzaghi et al., 2015b). These regional/local geoids can describe high-frequency features that are not generally included in global models, unless considering an ultra-high maximum spherical harmonic degree. However, this would imply a strong numerical regularization when computing spherical harmonic coefficients, because the high-resolution information is not homogeneously available at a global scale.

It is worth noticing that according to the Molodensky theory the height anomaly, i.e. the separation between the telluroid and the topography, is computed instead of the geoid (Sansò et al., 2019). The height anomaly can be converted to the geoid undulation, e.g. by using the Bouguer correction (Heiskanen and Moritz, 1967), or can be directly adopted as the height reference surface. In this case, the quasi-geoid is considered, that is the height anomaly mapped on the ellipsoid, and the national height systems are based on normal height instead of orthometric height. For the sake of simplicity, we will refer to both as geoid models hereafter, apart from when this distinction is strictly required.

Regional geoid models are typically given as point-wise values over geographical grids or over sparse points (Forsberg and Tscherning, 2008). Like in the case of global models, there is a strong need from the scientific community, but also from the civil society for engineering applications, to access regional geoid models. In the framework of the IAG, the International Service for the Geoid (ISG) has the task of providing open access to such information through the establishment and the maintenance of a geoid repository.

Regional geoid models are mainly used for height conversion from ellipsoidal heights to orthometric or normal heights, or vice versa (Sansò et al., 2019). The models stored in the geoid repository can be further used for crossvalidation, for comparison with global models, and, in general, for providing alternative solutions to the scientific community, different from the official ones that are typically released by national agencies. To reach these objectives, the ISG developed a specific website with a geographic database.

The geoids archived by the ISG correspond to countries or regions, and data can be accessed via a list or by selecting them on a map. The repository is under the process of being implemented through a database in the framework of a WebGIS. To provide interoperable and reusable models, the ISG focuses on the provision of clear and complete metadata (Chan and Zeng, 2006; Longhorn, 2005) and the use of open, standardized, and self-explanatory data formats (Cerri and Fuggetta, 2007).

The purpose of this paper is to introduce the reader to the service, by quickly revising the main steps of its history and its activities performed inside the geodetic community (Sect. 2). Section 3 focuses on the ISG services: (1) the geoid repository, explaining its structure and current status, and the data formats, with the description of the provided metadata; (2) the database indexing and DOI service; (3) the available height conversion online service; and (4) the schools on the geoid determination. Finally, some examples of possible assessments exploiting the available models, implementing comparisons, and computing statistics are provided in Sect. 4. The paper closes with some general considerations and future perspectives of the service.

\section{ISG, a service of the International Association of Geodesy}

The ISG is an official service of the IAG. It was founded in 1992 as the International Geoid Service (IGeS) with the aim to be one of the operative arms of the International Geoid Commission (IGeC). The service is provided by the main centre at Politecnico di Milano and by individual scientists. The ISG activities are in the framework of the International Gravity Field Service (IGFS), which includes other research centres and services: BGI (Bureau Gravimetrique International, France), ICGEM (International Centre for Global Earth Models, Germany), COST-G (International Combination Service for Time-variable Gravity Fields, Switzerland), IDEMS (International Digital Elevation Model Service, USA), and IGETS (International Geodynamics and Earth Tide Service, France).

The main tasks and activities of the ISG are as follows.

- Collect geoid estimates worldwide, validate them when possible, and disseminate them to users. Other auxiliary data, like global gravity models, useful for the geoid determination, may also be collected by the ISG, without redistributing them if they are already provided by other IAG services. Since summer 2020, the ISG has offered to assign digital object identifiers (DOIs) to its 
geoid models. This DOI service has been established in collaboration with GFZ Data Services and allows geoid models to be cited in publications (e.g. Barzaghi et al., 2020a, b).

- Collect, test, and, when allowed, distribute software for the geoid determination.

- Conduct research on methods for the geoid determination, also defining optimal procedures for merging the available data and models.

- Organize international schools on geoid determination addressing both theoretical and practical topics, possibly every 2 years. During the schools, students are trained in the use of the relevant software for geoid computation.

- Support agencies or scientists in computing local and regional geoid models, especially in developing countries, by also organizing special training courses.

- Disseminate training material and software on geoid computation, e.g. lecture notes of the schools.

- Issue Newton's Bulletin, which has a technical and applied nature, collecting papers and reports on gravity and geoid.

- Establish and update a website with the aim of presenting the service activities; showing and distributing the geoid models, software, and publications; and announcing news and schools on geoid determination. The geoid model distribution is also carried out via the catalogue of GFZ Data Services for the DOI-referenced models only.

- Provide users with online services through the website, like the height conversion service exploiting any of the publicly available geoid models in the geoid repository (see Sect. 3.2)

\section{ISG services}

The main services offered by the ISG are the geoid repository, the database indexing and DOI service, the height conversion online service, and the schools on the geoid determination. The first ones are data-oriented, while the latter is for educational purposes.

\subsection{The ISG geoid repository}

The ISG manages and preserves an openly accessible repository of regional, national, and continental geoid models at a worldwide scale. The repository aims at storing and redistributing geoid models in a standardized data format, also providing ancillary information useful for gravity-related analysis. Most models can be freely downloaded, some of them require the author's permission to be accessible, while a few are private and cannot be distributed. Consequently, they are classified as public, on-demand, or private, respectively. The ISG geoid repository currently ${ }^{1}$ stores 226 geoid models (158 gravimetric models, i.e. based on gravity data only, 8 geometric models, i.e. based on GPS/levelling data, and 60 hybrid models, i.e. based on both gravity and GPS/levelling data) under different policies (168 public, 21 on-demand, and 37 private). The repository is visited by about 500 worldwide users per month. The coverage area is almost worldwide, with resolution grids up to 0.5 arcmin as shown in Fig. 1 (on a $\log -10$ scale).

Particular attention is devoted to metadata and data interoperability. When stored, the geoids are collected both in the format provided by the owners and in ISG format, a standardized ASCII format developed on purpose. Details on this format will be given in the next subsection. Moreover, for each geoid, metadata are collected and archived, like the names of the authors, the publication year of the model, key reference publication(s), and a brief description on the computational method of the model. These pieces of information are then published on the website through the model-related web pages. An example of a model landing page is shown in Fig. 2.

The importance and the scientific relevance of such a service do not depend only on the amount and quality of available data but also on the completeness and clarity of the provided information. For this purpose, the ISG provides geoid models in a format that has been designed to be easily understood and managed by the final users.

\subsubsection{The ISG data format}

The ISG format provides local/regional geoid/quasi-geoid models given as undulations with respect to a reference ellipsoid on a grid or sparse points. The file is in ASCII format with the extension .isg. The first version of the ISG ASCII format was released in 2015 and updated in 2018 (version 1.01). In July 2020, a major new release, version 2.0, was published, mainly introducing more metadata to better characterize the content of the file and also allowing the storage of sparse point data. All the new models will be published with version 2.0. In addition, before an already published model is assigned with a DOI, it will be transformed in ISG ASCII version 2.0.

Each individual data file consists of three sections: (a) the optional comment section, starting at the beginning of the file and ending just before the keyword "begin_of_head"; (b) the header section, starting with the keyword "begin_of_head" and ending with the keyword "end_of_head", which contains textual and numerical parameters; and (c) the data section, starting just after the keyword "end_of_ head", which con-

\footnotetext{
${ }^{1}$ These statistics are based on the repository status on 10 November 2020 .
} 


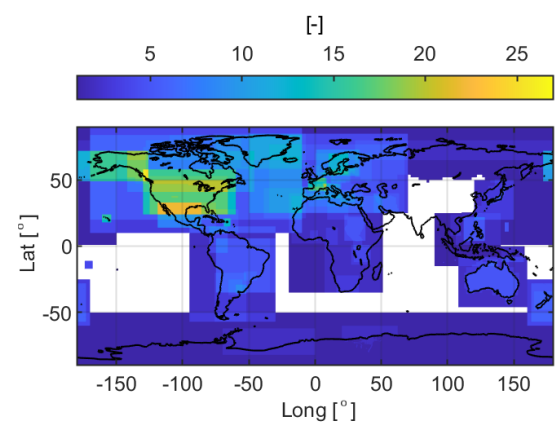

(a)

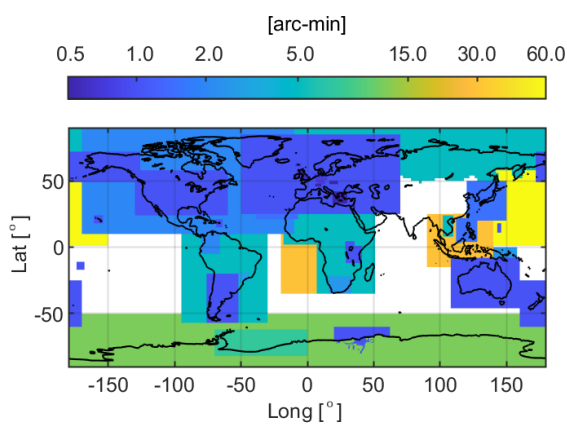

(b)

Figure 1. Geoid repository: (a) number of available geoid models covering the same area, where blank means missing data; (b) spatial resolution of the gridded geoid models available at the ISG, where the colour bar shows the highest spatial resolution available per location, on a $\log -10$ scale with units in arcmin.

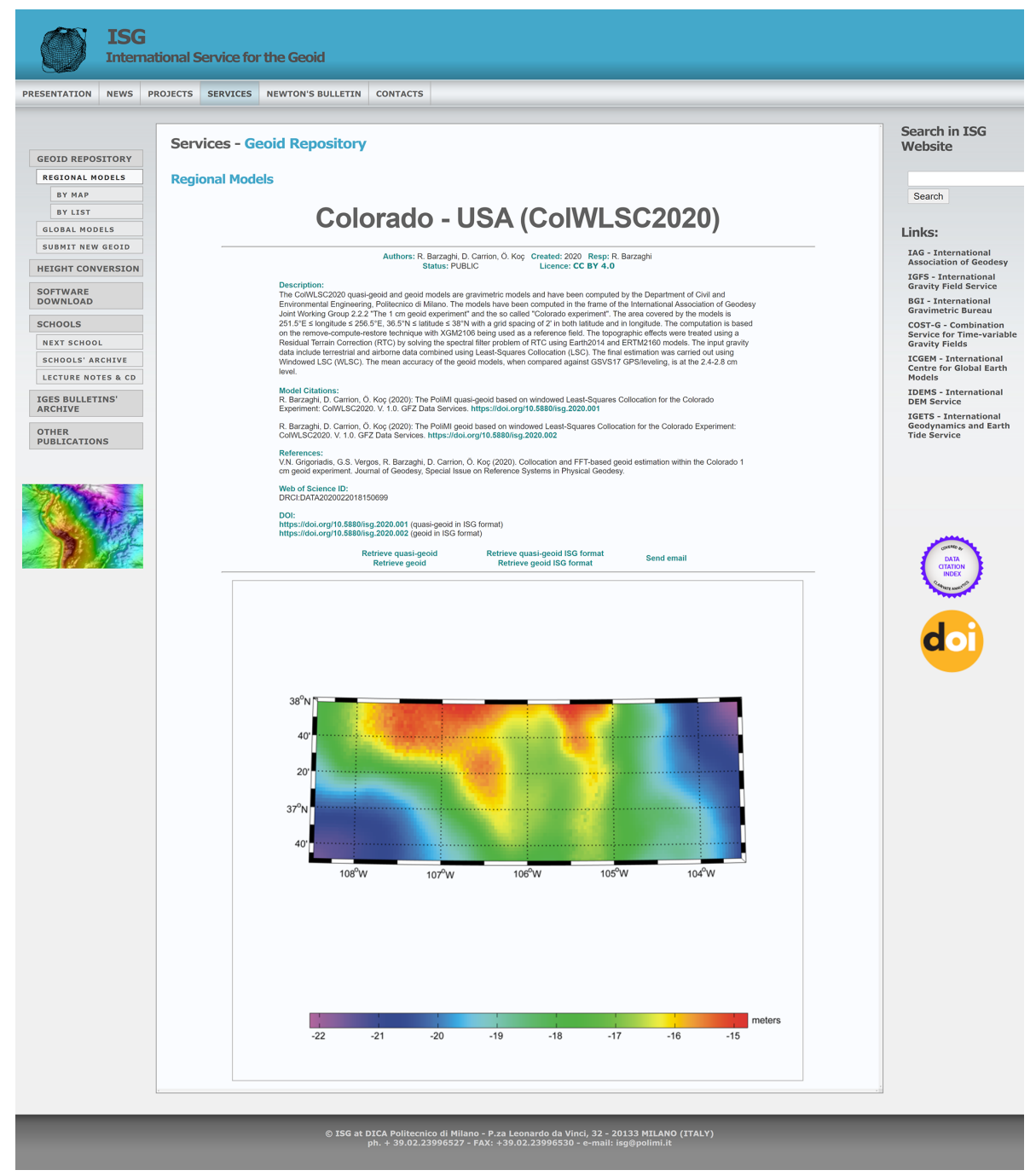

Figure 2. Example of a web page describing a model stored in the geoid repository. 
tains the undulation values. To increase data interoperability, sections (a) and (b) were designed with the same scheme of the .gfc file, distributed by ICGEM and providing global model coefficients (Ince et al., 2019).

In the comment section (a), three paragraphs are strongly recommended, the first one with the licence under which the data are distributed, the second one with the reference to cite when using the data, and the third one indicating the data provider and the institution distributing the model.

In the ISG format, the header section (b) is composed by structured metadata. It can be conceptually divided into three parts. The first contains textual metadata that are required to characterize the model, such as

- the name of the model and the year of computation;

- the type of the model (gravimetric, geometric, or hybrid);

- the classification between geoid and quasi-geoid;

- whether the data are sparse or gridded, and if gridded the ordering of the data;

- the reference ellipsoid and datum, the reference frame, and the tidal system;

- whether the coordinates are geodetic or projected and if projected the type of projection;

- the units of the undulation data and of the coordinates.

The second part contains numerical metadata that are mainly required to georeference the undulation values, such as

- the bounding box of the undulation dataset, i.e. minimum and maximum coordinates;

- the grid step and the number of rows and columns if the data are gridded (the number of rows can be used in sparse data to specify the number of points);

- the no-data value for missing points inside the grid structure.

Finally, the third part contains information about the file, such as the creation date and the format version. Metadata and their keywords depend on the format version. The file format specifications for all the possible versions are available at a dedicated page on the ISG website (https:// www.isgeoid.polimi.it/Geoid/format_specs.html, last access: 31 March 2021).

The data section was originally developed to contain the gridded undulation values, but from the format version 2.0 it is also possible to store sparse data by providing the point coordinates along with the undulation values. In case of gridded data, the point coordinates are defined in the header section, and the undulation values are always stored row by row, the default ordering being from north to south, with each row going from west to east.

\subsection{The ISG database indexing and DOI service}

The sharing of reliable, citable, and well-described research data are key elements for open science. The European Union is bringing the attention to the importance of data sharing and metadata through actions, policies, and directives, such as INSPIRE or the "European legislation on open data and the re-use of public sector information" (EU Open Data Directive). In addition, the new Horizon Europe programme, which is about to start, requires not only open access to research papers but also open access to the data. To effectively archive, discover, and access data, it is crucial to prepare and store complete metadata and to have access to well-known archives with a stable link. In addition, to grant proper credit to research authors, it is very important to allow for the data citation as well. Assigning digital object identifiers (DOIs) to research data is an important instrument for this and best practice for FAIR sharing data (e.g. Fenner et al., 2019; Hodson et al., 2018; Wilkinson et al., 2016; Data Citation Synthesis Group, 2014). Datasets with assigned DOIs are fully citable in scholarly literature that enables tracking of data usage via citation metrics and provides credit for researchers and institutions.

For these reasons, the ISG has established agreements with (1) Clarivate's Data Citation Index ${ }^{\mathrm{TM}}$ (https://clarivate.com/webofsciencegroup/solutions/

webofscience-data-citation-index/, last access: 31 March 2021) and (2) with GFZ Data Services (https://dataservices.gfz-potsdam.de/portal/, last access: 31 March 2021), the research data repository for the Geosciences domain, hosted at GFZ German Research Centre for Geosciences (https://www.gfz-potsdam.de/en/home/, last access: 31 March 2021).

\subsubsection{Data Citation Index}

Clarivate's "Data Citation Index ${ }^{\mathrm{TM}}$ " serves as the "single point of access to quality research data from global repositories across disciplines" that are "linked to literature articles in the Web of Science ${ }^{\mathrm{TM}}$." (https://clarivate.com/webofsciencegroup/ solutions/webofscience-data-citation-index/, last access: 31 March 2021). Geoid models of the ISG are indexed in the Data Citation Index, and the accession number is indicated on the geoid model website (see lower left of Fig. 3).

\subsubsection{DOI service}

Since summer 2020, the ISG, in collaboration with GFZ Data Services, has extended its services by offering the assignment of DataCite DOIs to geoid models archived in the ISG geoid repository. This includes the generation and provision of standardized, machine-readable metadata following international standards (DataCite, ISO19115) that are complementary to the disciplinary metadata already collected for 


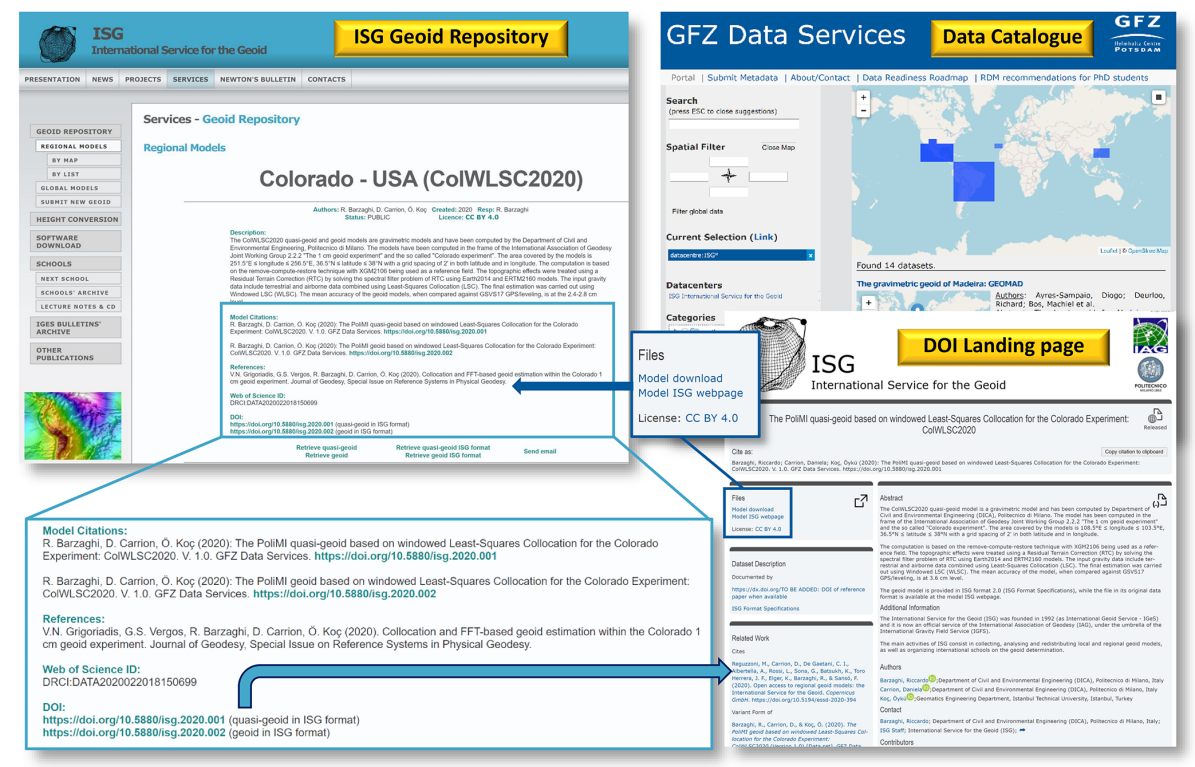

Figure 3. Overview on the relation between the ISG and GFZ Data Services for DOI-referenced geoid models of the Colorado experiment (ColWLSC2020). This project includes a quasi-geoid model (Barzaghi et al., 2020a) and a geoid model (Barzaghi et al., 2020b). Both models can be accessed via the dedicated web page in the ISG geoid repository (on the left) and via the DOI landing pages in GFZ Data Services (on the right). The "File" section of the DOI landing page includes the links to the model file and the corresponding web page in the ISG repository. On the other side, the ISG model web page is enhanced with the recommended citations of the DOI-assigned models and the links to the DOI landing pages at GFZ Data Services. The arrows show the cross-references between the two web pages.

ISG geoid models and openly accessible via a standard application programming interface (API). An individual DOI is assigned to each geoid (or quasi-geoid) model by GFZ Data Services, which also serves as an additional archive of the ISG repository. The agreed licence for geoid models is the Creative Commons Attribution 4.0 (CC BY 4.0) Licence. As already stated, the model data are converted to the ISG 2.0 format before the DOI assignment, thus including the model citation and licence information in the comment section of the file. Geoid models assigned with DOI can be additionally discovered via the catalogue of GFZ Data Services and via the repository machine-readable DOI landing pages that are embedding schema.org (https://schema.org/, last access: 31 March 2021). To this aim, GFZ Data Services has created a new internal "datacentre" for ISG geoid models (https://dataservices.gfz-potsdam.de/portal/, last access: 31 March 2021). The DOI landing pages at GFZ Data Services are closely cross-linked with the model pages at the ISG, as well as with key articles or reports describing the geoid models. Different types of models, e.g. geoids and quasi-geoids or gravimetric and hybrid solutions, computed in the same framework are cross-referenced on the DOI landing pages and in the DataCite metadata of each model. The DOI links are also added to the model pages at the ISG (see Fig. 3). All the DOI-referenced regional geoid models of the ISG are listed in Table A1 and can also be accessed via https://dataservices.gfz-potsdam.de/portal/?fq= subject:isg (last access: 31 March 2021).

\subsection{The ISG height conversion web service}

The ISG offers a height conversion web service to the users. They can provide the coordinates of one or more points (in the latter case through a CSV file containing three columns, namely latitude, longitude, and height to be converted), and, after selecting the geoid model and the interpolation method, the web service returns the conversion from ellipsoidal to orthometric height or vice versa. Once the user provides the point coordinates, only the geoid models containing at least one of these points are listed and can be selected by the user for the height conversion. This is possible by exploiting the model bounding box information that is available in the model file header as defined according to the ISG format.

As for the algorithmic point of view, the conversion is based on the formula $H=h-N$, relating the ellipsoidal height $h$ and the orthometric height $H$ through the geoid undulation $N$. Due to the fact that geoid models used by this service are given on a grid, the currently available interpolation methods are a bilinear interpolation among the four closest grid knots to the input point and the inverse distance weighting interpolation. Other interpolation methods will be made available in the future.

As for the software implementation point of view, the web service is divided into front end and back end, with the former providing a user interface and the latter performing the calculations. The front end is the "visible" part of the application; it is implemented by using an HTML page and 


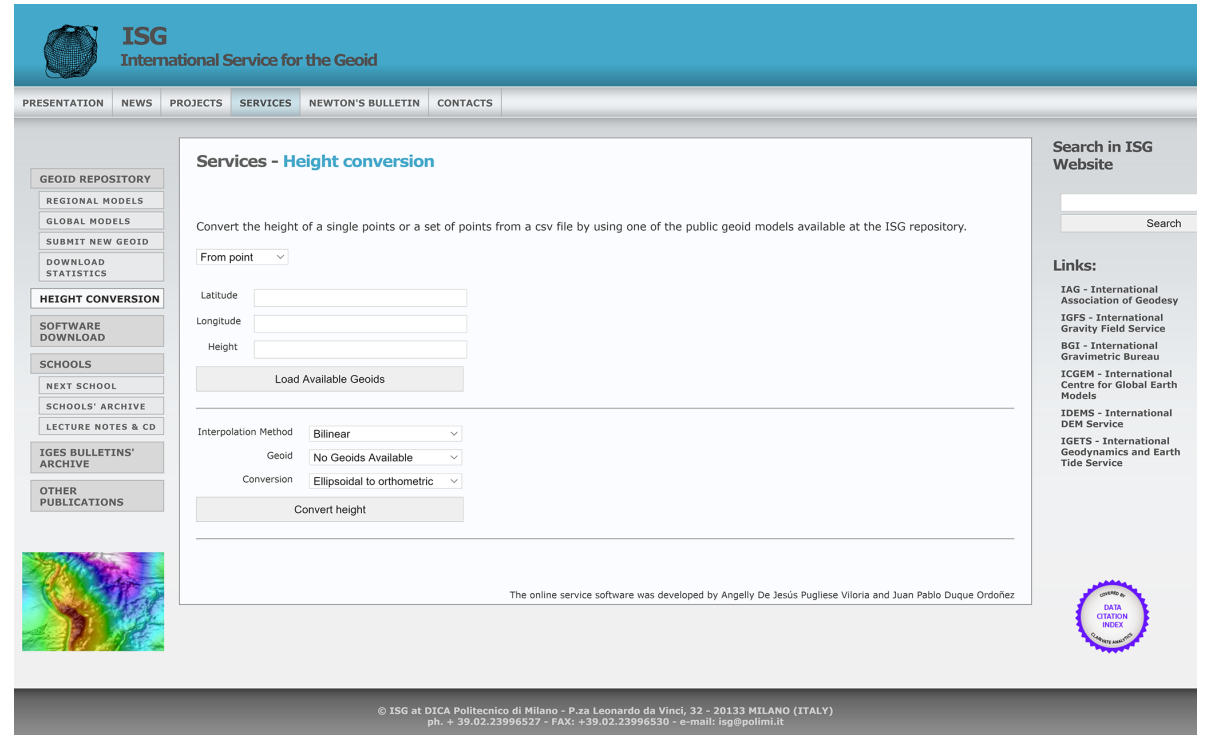

Figure 4. Web page to access the ISG height conversion web service.

JavaScript. The HTML page contains a form with all the needed fields for the height conversion according to the web service created on the back end (see Fig. 4). The interface is designed to change as the user interacts with the application and selects the different options (single or multiple point coordinates). There are also checks on the input file size and format when the user asks for the conversion of more than one point.

The back end is the core of the web service, performing the required computation without increasing the burden of the front end. In this way the web service can be modified or updated without interfering with the front end. In order to implement the back end, a REST API (Representational State Transfer Application Programming Interface) was created in Django, a high-level Python web framework that allows mathematical calculations using Python with the NumPy library. Four different endpoints were created for the geoid model research and the height conversion, for both a single point and a set of points. A sketch of the logical structure of this web service is provided in Fig. 5.

All requests from the front end to the back end rely on the HTTP POST method, i.e. enclosing the data in the body of the request messages instead of storing it, while the answers from the back end are transmitted through a JSON file, which is directly visualized in the HTML page.

\subsection{Geoid schools}

Geoid schools, i.e. the organization and support of technical schools on geoid estimation and related topics, are the earliest and central educational task of the ISG. Beginning with the first international school on "the determination and use of the geoid" (1994 in Milan), the ISG geoid schools have be-

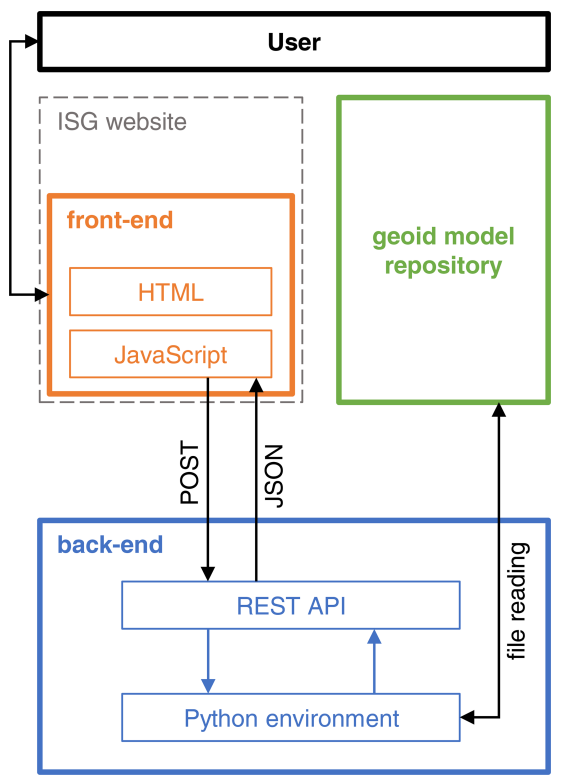

Figure 5. Logical structure of the height conversion web service.

come an international reference for geoid computation training and gravity field modelling. The general purpose of the full-week intensive geoid school is to prepare graduate students, young researchers, employees of national agencies and services, or industry staff for the computation and usage of gravimetric geoid models for scientific and technical applications in geodesy. The schools provide a good opportunity to familiarize with the latest developments in geoid determination and to improve international contacts and collaborations among scientists dealing with gravity field modelling. The- 
Table 1. List of the geoid schools organized by the ISG since its foundation.

\begin{tabular}{llc}
\hline Location & Date & Attendees \\
\hline Mongolian University of Science and Technology, Ulaanbaatar (MNG) & 6-10 June 2016 & 30 \\
Universidad Técnica Particular de Loja, Loja (ECU) & 7-11 October 2013 & 15 \\
Research Institute Elektropribor, St. Petersburg (RUS) & 28 June-2 July 2010 & 15 \\
National University of La Plata, La Plata (ARG) & $7-11$ September 2009 & 23 \\
Politecnico di Milano, Como Campus, Como (ITA) & 15-19 September 2008 & 25 \\
Niels Bohr Institute, University of Copenhagen, Copenhagen (DNK) & 19-23 June 2006 & 24 \\
Budapest University of Technology and Economics, Budapest (HUN) & 31 January-5 February 2005 & 49 \\
University of Thessaloniki, Thessaloniki (GRC) & 30 August-5 September 2002 & 30 \\
Department of Survey and Mapping Malaysia, Johor - Bahru (MYS) & 21-25 February 2000 & 41 \\
Politecnico di Milano, Milan (ITA) & 15-19 February 1999 & 23 \\
Instituto Brasileiro de Geografia e Estatística, Rio de Janeiro (BRA) & 10-16 September 1997 & 31 \\
Politecnico di Milano, Milan (ITA) & 10-14 October 1994 & 34 \\
\hline
\end{tabular}

oretical lectures are followed by computer exercises using software that is also distributed by the ISG.

The general frame of the lectures is the following:

- introduction to physical geodesy,

- computation and use of high degree and ultra-highdegree geopotential models,

- geoid computation using Stokes' integral and collocation,

- terrain effects in geoid estimation,

- fast Fourier transform (FFT) techniques in geodesy,

- seminars on specific topics depending on the research fields of the guest tutors.

Lecture notes of the courses are distributed to the participants, as well as the required software and the exercises. Such material can also be provided upon request through the ISG website. Since 1994, 12 editions of the geoid school have been organized, held in 10 countries, and attended by 340 people (see Table 1). The next edition was scheduled in 2020, but it was postponed because of the Covid-19 pandemic.

Beyond the international geoid schools, ad hoc training periods are also carried out by the ISG in order to support foreign institutions and scientists in the field of geoid computation.

\section{Geoid comparative analyses based on the ISG repository}

Relative comparisons can be carried out between the available geoids stored in the ISG repository. Such comparisons can reveal useful information, like possible mismatches between estimated geoids, for example when two models referring to the same area are computed at different epochs or with different techniques or published by different authors. Additionally, local or regional models can be compared with global gravitational models. In the following, examples of such relative assessments are described.

\subsection{Comparison of local geoid models over the same area}

As an example of evolution over time, the Japanese geoid can be considered. The ISG geoid repository collected several versions of Japanese national geoids computed by the Geographical Survey Institute. Among them, the group of hybrid geoids published in 1996, 2000, and 2011 can be compared to evaluate their evolution over time. The first geoid is GSIGEO96 (Fukuda et al., 1997). It is provided on a $3^{\prime} \times 3^{\prime}$ grid, and its reference ellipsoid is GRS80 in the ITRF89 frame (Fig. 6a). It has been computed by fitting the JGEOID93 gravimetric geoid model to the 806 sites of the nationwide GPS/levelling network via least-squares collocation (LSC). The second geoid, named GSIGEO2000 (Kuroishi, 2000), is provided on a $1^{\prime} \times 1.5^{\prime}$ grid, and its reference ellipsoid is GRS80 in the ITRF94 frame at epoch 1997.0 (Fig. 6b), i.e. the Japanese Geodetic Datum 2000 (JGD2000). It has been computed by fitting the JGEOID2000 gravimetric geoid model to the nationwide network of GPS/levelling data via LSC. The third geoid is the GSIGEO2011 (Miyahara et al., 2014). Again, this model is provided on a $1^{\prime} \times 1.5^{\prime}$ grid, and its reference ellipsoid is GRS80 in the ITRF94 frame at epoch 1997.0 (Fig. 6c), i.e. the Japanese Geodetic Datum 2000 (JGD2000). In this case, it has been computed by fitting the JGEOID2008 gravimetric geoid model to GNSS/levelling data at 971 sites (786 GEONET stations, 156 benchmarks, and 29 tidal stations) via LSC.

Due to the different spatial resolutions and grid boundaries, the comparison has been done stepwise by interpolating the most recent geoid on the same grid of the previous model. Once the grids have been made consistent, a plane fitting their differences has been estimated and removed before 


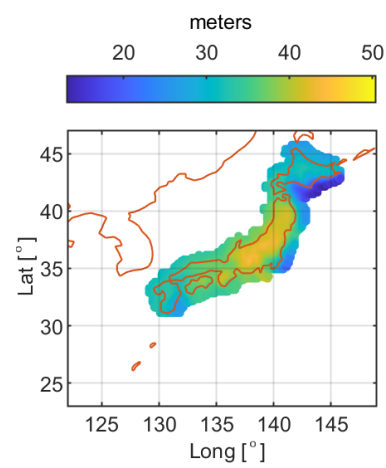

(a)

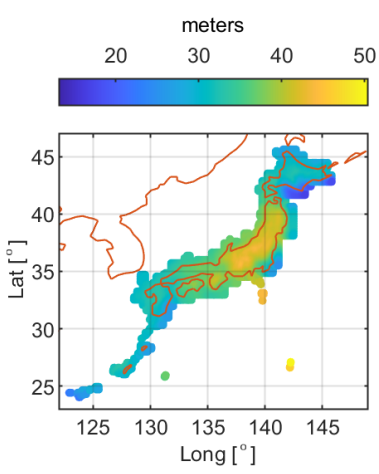

(b)

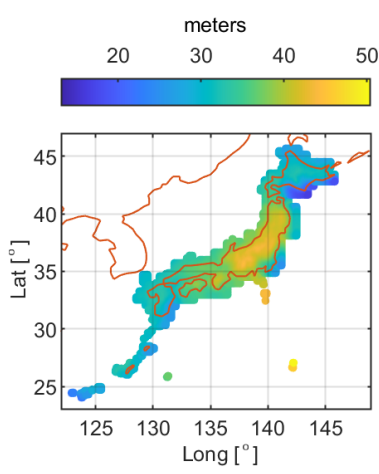

(c)

Figure 6. Evolution of Japanese geoid models over time. The three panels represent the geoid undulation with respect to the reference ellipsoid of (a) GSIGEO96, (b) GSIGEO2000, and (c) GSIGEO2011.

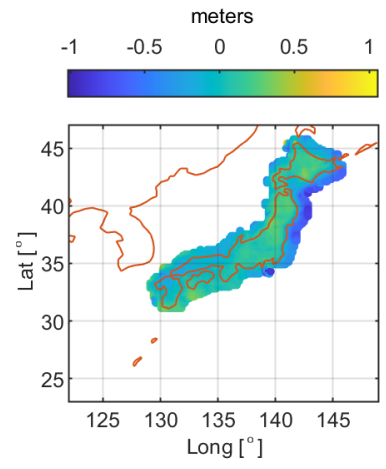

(a)

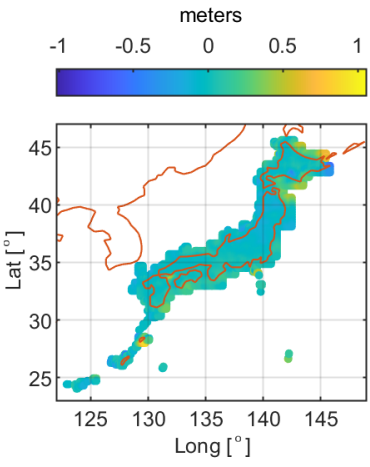

(b)

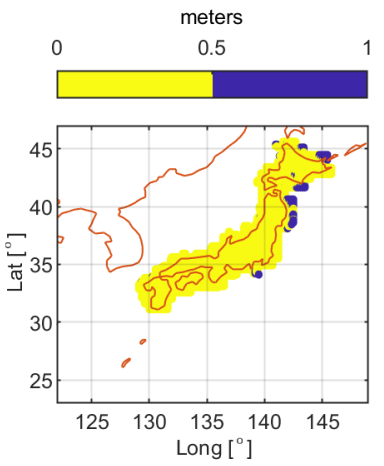

(c)

Figure 7. Difference between the analysed Japanese geoids. (a) GSIGEO96-GSIGEO2000; (b) GSIGEO2000-GSIGEO2011; (c) combined agreement between the considered Japanese geoids. In yellow areas the difference between GSIGEO96-00 and GSIGEO00-11 is less than $50 \mathrm{~cm}$, while in blue areas it is more than $50 \mathrm{~cm}$.

statistics computation. This was done to reduce the impact of possible mismatches due to different reference frames and height datums. Table 2 shows the main statistics of the differences between two consecutive versions of the same geoid model.

From these statistics, it can be noted that the two refinements of the GSIGEO geoid model have a different impact. The standard deviation of the residuals between the "editions" 1996 and 2000 is almost $19 \mathrm{~cm}$ while between the "editions" 2000 and 2011 it is halved, about $10 \mathrm{~cm}$. This is mainly due to a better quality and larger terrestrial gravity database and also to an increase in the computational power that allowed the better determination of the short-wavelength behaviour around the consolidated longwavelength estimates of the gravity field. It is interesting to look at the spatial distribution of the residuals, shown in Fig. 7. Referring to the differences between GSIGEO96 and GSIGEO00 (called GSIGEO96-00), high-amplitude residuals are concentrated along the eastern border, with values down to about $-1.0 \mathrm{~m}$; referring to the differences between GSIGEO00 and GSIGEO11 (called GSIGEO00-11), resid- uals are generally smaller but still localized in the eastern and northern borders, with opposite amplitude with respect to GSIGEO96-00; areas where residuals of GSIGEO96-00 and GSIGEO00-11 are different for more than $50 \mathrm{~cm}$ suggest disagreement between the two refinements.

\subsection{Comparison of local geoids with global models}

The agreement between local and global models can be assessed too. Global models can be used at their full resolution to synthesize the geoid at arbitrary points of a local area. This is an advantage with respect to local geoids but at the cost of possible mismodelling of local features. The comparison between local and global geoids at the same points gives the possibility of detecting those areas where the contribution of local geoids is more prominent. Figure 8 presents three geoid models taken as an example for such an assessment.

The first model is the recent ColWLSC2020 (Barzaghi et al., 2020b) gravimetric geoid model, computed by the Department of Civil and Environmental Engineering, Politecnico di Milano. This model has been computed in the frame 
Table 2. Statistics of the differences between the analysed Japanese geoids.

\begin{tabular}{llrrrr}
\hline Geoid A & Geoid B & Grid resolution & SD $(\mathrm{m})$ & Min $(\mathrm{m})$ & Max $(\mathrm{m})$ \\
\hline GSIGEO96 & GSIGEO2000 & $3^{\prime} \times 3^{\prime}$ & 0.184 & -1.017 & 1.060 \\
GSIGEO2000 & GSIGEO2011 & $1^{\prime} \times 1.5^{\prime}$ & 0.104 & -0.610 & 0.891 \\
\hline
\end{tabular}

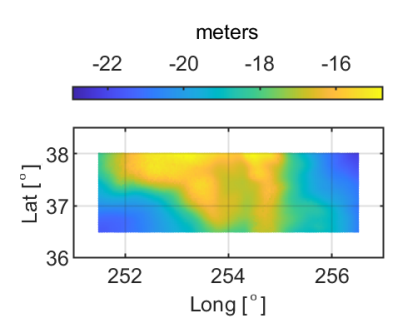

(a)

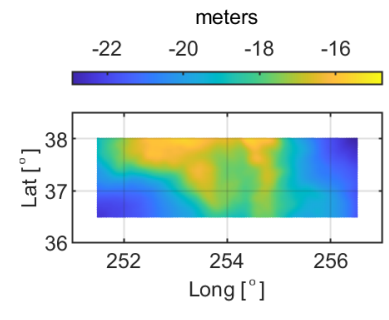

(b)

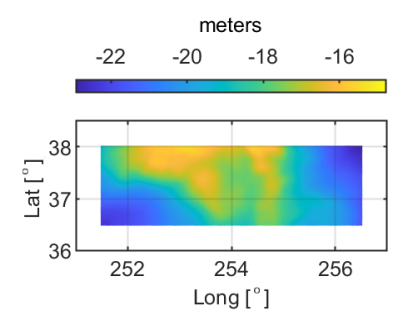

(c)

Figure 8. Local and global geoid models. The three panels show the geoid undulation over the Colorado (US) area with respect to the reference ellipsoid of (a) ColWLSC2020, (b) EIGEN-6C4, and (c) EGM2008.

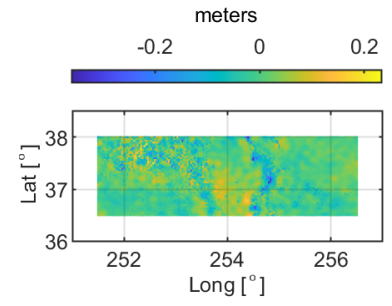

(a)

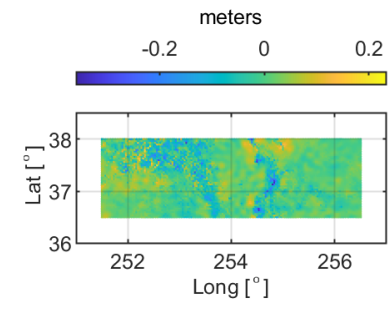

(b)

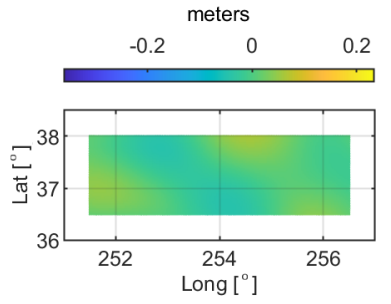

(c)

Figure 9. Difference between the analysed Colorado geoids: (a) ColWLSC2020-EIGEN-6C4, (b) ColWLSC2020-EGM2008, and (c) EIGEN-6C4-EGM2008.

of the International Association of Geodesy Joint Working Group 2.2.2 "The $1 \mathrm{~cm}$ geoid experiment" and the so-called "Colorado experiment". The area covered by the model is $251.5^{\circ} \mathrm{E} \leq$ longitude $\leq 256.5^{\circ} \mathrm{E}, 36.5^{\circ} \mathrm{N} \leq$ latitude $\leq 38^{\circ} \mathrm{N}$ with a grid spacing of $2^{\prime}$ in both latitude and longitude. The computation is based on the remove-compute-restore technique, with XGM2016 (Pail et al., 2017) being used as a reference field. The topographic effects were treated using a residual terrain correction (RTC) by solving the spectral filter problem of RTC using the Earth2014 and ERTM2160 models. The input gravity data include terrestrial and airborne data that were combined by least-squares collocation (LSC). The final estimation was carried out using windowed LSC (WLSC). The mean accuracy of the geoid model, when compared against GSVS17 GPS/levelling, is at the $2.4-2.8 \mathrm{~cm}$ level. The second and third models are two of the most widespread global geoid models, namely EIGEN-6C4 (Förste et al., 2014) and EGM2008 (Pavlis et al., 2012), both computed up to degree and order 2190 on the same $2^{\prime} \times 2^{\prime}$ grid of ColWLSC2020.

For their comparison, a plane fitting their differences has been estimated and removed to reduce the impact of possi- ble mismatches due to different reference frames and height datums. Table 3 shows the main statistics of the differences between these three geoid models.

From these statistics, it can be noted that over this area the two global models agree quite well, with differences of a few centimetres at most. When compared to the local model, the amplitude of the differences increases by an order of magnitude with a standard deviation that becomes almost double the standard deviation of the residuals between the two global models. Figure 9 shows the spatial distribution of the geoid residuals.

As one can see, the main differences can be found on the Rocky Mountains along the meridian at $255^{\circ} \mathrm{E}$ and, in smaller part, in the north-western region of the considered area. Taking into account that the standard deviations $\sigma$ of the residuals between the local geoid model and the two global models are almost identical, the agreement between these models can be evaluated on the basis of the percentage of grid points where all three models differ by less than $1 \sigma, 2 \sigma$, or $3 \sigma$. As shown in Fig. 10, $70 \%$ of the points differ by less than $0.049 \mathrm{~m}, 93 \%$ by less than $0.098 \mathrm{~m}$, and $98 \%$ by less than $0.147 \mathrm{~m}$. 
Table 3. Statistics of the differences between the analysed Colorado geoids.

\begin{tabular}{llrrrr}
\hline Geoid A & Geoid B & Grid resolution & SD $(\mathrm{m})$ & Min $(\mathrm{m})$ & Max $(\mathrm{m})$ \\
\hline ColWLSC2020 & EIGEN-6C4 & $2^{\prime} \times 2^{\prime}$ & 0.047 & -0.360 & 0.234 \\
ColWLSC2020 & EGM2008 & $2^{\prime} \times 2^{\prime}$ & 0.049 & -0.355 & 0.209 \\
EIGEN-6C4 & EGM2008 & $2^{\prime} \times 2^{\prime}$ & 0.025 & -0.046 & 0.061 \\
\hline
\end{tabular}

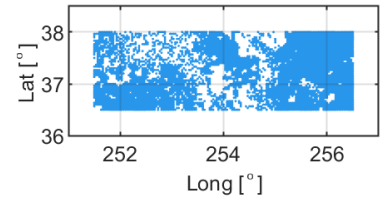

(a)

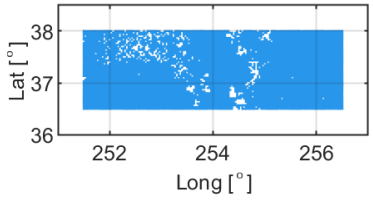

(b)

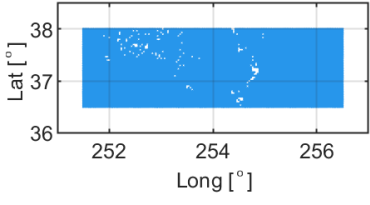

(c)

Figure 10. Agreement of the local Colorado geoid model with respect to both global models: (a) residuals below $1 \sigma$, (b) residuals below $2 \sigma$, and (c) residuals below $3 \sigma$ are shown in blue.

Since the model ColWLSC2020 compared against GSVS17 GPS/levelling has residuals of about $2.5 \mathrm{~cm}$ standard deviation, it might be that the global models suffer from missing information in the Colorado area, making the local geoid model more reliable for investigations requiring a high level of accuracy. Note also that the two global models have small differences in this area as they contain the same terrestrial gravity dataset.

\section{Data availability}

All geoid models used in this analysis are freely accessible via the ISG geoid repository where they can be discovered via an alphabetical list or a map (https: //www.isgeoid.polimi.it/Geoid/geoid_rep.html, last access: 31 March 2021). All the DOI-referenced regional geoid models of the ISG are listed in Table A1 and can also be accessed via GFZ Data Services (https://dataservices.gfz-potsdam.de/ portal/?fq=subject:isg, last access: 31 March 2021).

\section{Conclusions}

The ISG is an official worldwide IAG service hosted at Politecnico di Milano aiming at supporting the geodetic community. One of the main activities of the ISG is to collect and redistribute regional geoid models at a worldwide scale, providing users with geoid models published by different authors, at different spatial resolutions, referring to different editions and areas, from local to continental scales. Before dissemination, the geoids collected in the ISG repository are validated and harmonized through a pre-processing step that converts all available data into a unique file format. Since its foundation in 1992, the ISG has promoted the education for geoid computation, through international schools and special training courses on geoid estimation. The availability of one worldwide archive of local and regional geoids allows one to easily find, access, and exploit these models, but also to perform comparative analyses in a research perspective. For instance, one can compare the evolution over time of the same geoid model, as shown in this paper with the assessment of the Japanese geoids of the GSIGEO series. Another example has been provided by comparing a local geoid model stored in the ISG repository with the corresponding counterpart synthetized from global models stored in the ICGEM repository, covering the Colorado (USA) region which has been recently used as a test field for an IAG study on geoid determination. The ISG is continuously enriching its geoid repository in order to offer users the widest possible panorama of the geoid models available worldwide and organizing the next geoid schools to support the geodetic community.

Concerning future plans, we will work on improving both the data platform and the data exploitation. As for the website, the idea is to transform the geoid repository into a WebGIS with a more organized database, thus allowing geographical queries. This also implies an optimized storage of the geoid models as well as the development of other web services to access the data and to compare them with other databases, e.g. global models from the ICGEM website. As for the data exploitation, we would like to increase the number of potential users, especially for administrative and commercial applications. This means making the ISG a recognized and certified reference institution not only for the scientific community, e.g. by delivering output products that can be directly assimilated by commercial software and devices such as GNSS receivers. 


\section{Appendix A}

Table A1. Overview of ISG geoid models that have already been labelled with DOIs (as of 31 March 2021).

\begin{tabular}{|c|c|c|c|c|}
\hline Model name & Model type & Year & DOI & Citation \\
\hline $\begin{array}{l}\text { Brazil } \\
\text { (MAPGEO2004) }\end{array}$ & gravimetric geoid & 2004 & https://doi.org/10.5880/isg.2004.002 & Lobianco et al. (2004) \\
\hline $\begin{array}{l}\text { Brazil } \\
\text { (MAPGEO2010) }\end{array}$ & gravimetric geoid & 2010 & https://doi.org/10.5880/isg.2010.002 & de Matos et al. (2010) \\
\hline $\begin{array}{l}\text { Brazil } \\
\text { (MAPGEO2015) }\end{array}$ & gravimetric geoid & 2015 & https://doi.org/10.5880/isg.2015.001 & Blitzkow et al. (2015) \\
\hline Colorado - USA & gravimetric quasi-geoid & 2020 & https://doi.org/10.5880/isg.2020.001 & Barzaghi et al. (2020a) \\
\hline (ColWLSC2020) & gravimetric geoid & 2020 & https://doi.org/10.5880/isg.2020.002 & Barzaghi et al. (2020b) \\
\hline Colorado - USA & gravimetric quasi-geoid & 2020 & https://doi.org/10.5880/isg.2020.003 & Grigoriadis and Vergos (2020a) \\
\hline (ColFFTWG2020) & gravimetric geoid & 2020 & https://doi.org/10.5880/isg.2020.004 & Grigoriadis and Vergos (2020b) \\
\hline $\begin{array}{l}\text { Madeira } \\
\text { (GEOMAD) }\end{array}$ & gravimetric geoid & 2015 & https://doi.org/10.5880/isg.2015.002 & Ayres-Sampaio et al. (2015) \\
\hline $\begin{array}{l}\text { Mexico } \\
(\text { GGM04) }\end{array}$ & gravimetric geoid & 2004 & https://doi.org/10.5880/isg.2004.001 & Avalos Naranjo et al. (2004) \\
\hline $\begin{array}{l}\text { Mexico } \\
(\text { GGM05) }\end{array}$ & gravimetric geoid & 2005 & https://doi.org/10.5880/isg.2005.001 & Avalos Naranjo et al. (2005) \\
\hline $\begin{array}{l}\text { Mexico } \\
\text { (GGM06) }\end{array}$ & gravimetric geoid & 2006 & https://doi.org/10.5880/isg.2006.001 & Avalos Naranjo et al. (2006) \\
\hline $\begin{array}{l}\text { Mexico } \\
(\text { GGM10) }\end{array}$ & gravimetric geoid & 2010 & https://doi.org/10.5880/isg.2010.001 & Avalos Naranjo et al. (2010) \\
\hline Taiwan & gravimetric geoid & 2018 & https://doi.org/10.5880/isg.2018.001 & Hwang et al. (2018a) \\
\hline (TWGEOID2018) & hybrid geoid & 2018 & https://doi.org/10.5880/isg.2018.002 & Hwang et al. (2018b) \\
\hline
\end{tabular}


Author contributions. MR, DC, CIDG, AA, and LR conceived and drafted the manuscript, with contributions by GS, KB, JFTH, $\mathrm{KE}, \mathrm{RB}$, and FS. All authors revised the manuscript before the submission and during the review process that were both coordinated by CIDG. FS founded the ISG in 1992. FS, RB, MR, GS, and DC managed the service during these years. GS and DC realized the website. MR and LR currently maintain the geoid repository, with developments by JFTH. MR, LR, DC, and RB defined the data format. KE, MR, DC, and LR developed the DOI services and are responsible for the DOI assignment to the geoid models. LR and MR supervised the height conversion service development. FS, RB, and GS organized and contributed to the international geoid schools. CIDG and KB performed the computations for the geoid comparative analysis.

Competing interests. The authors declare that they have no conflict of interest.

Acknowledgements. The authors are grateful to Cinzia Vajani for the website maintenance, Angelly De Jesús Pugliese Viloria and Juan Pablo Duque Ordoñez for the implementation of the height conversion service, and all those who shared their geoid models through the ISG repository.

Review statement. This paper was edited by Christian Voigt and reviewed by two anonymous referees.

\section{References}

Avalos Naranjo, D., Hernández Navarro, A., Muñoz Abundes, R., and Sosa Gaytán, M.: The Mexican gravimetric geoid: GGM04, GFZ Data Services, https://doi.org/10.5880/ISG.2004.001, 2004.

Avalos Naranjo, D., Hernández Navarro, A., Muñoz Abundes, R., and Sosa Gaytán, M.: The Mexican gravimetric geoid: GGM05, GFZ Data Services, https://doi.org/10.5880/ISG.2005.001, 2005.

Avalos Naranjo, D., Hernández Navarro, A., Muñoz Abundes, R., and Sosa Gaytán, M.: The Mexican gravimetric geoid: GGM06, GFZ Data Services, https://doi.org/10.5880/ISG.2006.001, 2006.

Avalos Naranjo, D., Sosa Gaytán, M., and Muñoz Abundes, R.: The Mexican gravimetric geoid: GGM10, GFZ Data Services, https://doi.org/10.5880/ISG.2010.001, 2010.

Ayres-Sampaio, D., Deurloo, R., Bos, M., Magalhães, A., and Bastos, L.: The gravimetric geoid of Madeira: GEOMAD, GFZ Data Services, https://doi.org/10.5880/ISG.2015.002, 2015.

Barzaghi, R., Migliaccio, F., Reguzzoni, M., and Albertella, A.: The Earth gravity field in the time of satellites, Rendiconti Lincei, 26, 13-23, https://doi.org/10.1007/s12210-015-0382-9, 2015a.

Barzaghi, R., Carrion, D., Reguzzoni, M., and Venuti, G.: A feasibility study on the unification of the Italian height systems using GNSS-leveling data and global satellite gravity models, in: IAG 150 Years, edited by: Rizos, C. and Willis, P., International Association of Geodesy Symposia, 143, 281-288, Springer, Cham, https://doi.org/10.1007/1345_2015_35,2015b.

Barzaghi, R., Carrion, D., and Koç, Ö.: The PoliMI quasigeoid based on windowed Least-Squares Collocation for the
Colorado Experiment: ColWLSC2020, GFZ Data Services, https://doi.org/10.5880/isg.2020.001, 2020a.

Barzaghi, R., Carrion, D., and Koç, Ö.: The PoliMI geoid based on windowed Least-Squares Collocation for the Colorado Experiment: ColWLSC2020, GFZ Data Services, https://doi.org/10.5880/isg.2020.002, 2020b.

Bingham, R. J., Haines K., and Hughes C. W.: Calculating the ocean's mean dynamic topography from a mean sea surface and a geoid, J. Atmos. Ocean. Tech., 25, 1808-1822, https://doi.org/10.1175/2008JTECHO568.1, 2008.

Blitzkow, D., de Matos, A. C. O. C., Machado, W. C., Nunes, M. A., Lengruber, N. V., Xavier, E. M. L., and Fortes, L. P. S.: The Brazilian gravimetric geoid: MAPGEO2015, GFZ Data Services, https://doi.org/10.5880/ISG.2015.001, 2015.

Cerri, D. and Fuggetta, A.: Open standards, open formats, and open source, J. Syst. Softw., 80, 11, 1930-1937, https://doi.org/10.1016/j.jss.2007.01.048, 2007.

Chan, L. M. and Zeng, M. L.: Metadata interoperability and standardization - A study of methodology Part 1, D-Lib Magazine, 12, 6, https://doi.org/10.1045/june2006-zeng, 2006.

Data Citation Synthesis Group: Joint declaration of data citation principles, FORCE11, https://doi.org/10.25490/a97f-egyk, 2014.

de Matos, A. C. O. C., Blitzkow, D., Guimarães, G. do N., Lobianco, M. C. B., and Costa, S. M. A.: The Brazilian gravimetric geoid: MAPGEO2010, GFZ Data Services, https://doi.org/10.5880/ISG.2010.002, 2010.

Fenner, M., Crosas, M., Grethe, J. S., Kennedy, D., Hermjakob, H., Rocca-Serra, P., Durand, G., Berjon, R., Karcher, S., Martone, M., and Clark, T.: A data citation roadmap for scholarly data repositories, Sci. Data, 6, 28, https://doi.org/10.1038/s41597019-0031-8, 2019.

Förste, C., Bruinsma, Sean. L., Abrikosov, O., Lemoine, J.-M., Marty, J. C., Flechtner, F., Balmino, G., Barthelmes, F., and Biancale, R.: EIGEN-6C4 The latest combined global gravity field model including GOCE data up to degree and order 2190 of GFZ Potsdam and GRGS Toulouse, GFZ Data Services, https://doi.org/10.5880/ICGEM.2015.1, 2014.

Forsberg, R. and Tscherning, C. C.: Overview manual for the GRAVSOFT Geodetic Gravity Field Modelling Programs, 2nd Edn. Technical report, DTU-Space, 2008.

Fukuda, Y., Kuroda, J., Takabatake, Y., Itoh, J., and Murakami, M.: Improvement of JGEOID93 by the geoidal heights derived from GPS/leveling survey, in: Gravity, Geoid and Marine Geodesy, edited by: Segawa, J., Fujimoto, H., and Okubo, S., International Association of Geodesy Symposia, 117, 589-596, Springer Verlag, https://doi.org/10.1007/978-3-662-03482-8_78, 1997.

Grigoriadis, V. N. and Vergos, G. S.: The AUTh quasi-geoid based on 1D FFT with Wong-Gore modification of the Stokes kernel for the Colorado Experiment: ColFFTWG2020, GFZ Data Services, https://doi.org/10.5880/ISG.2020.003, 2020a.

Grigoriadis, V. N. and Vergos, G. S.: The AUTh geoid based on 1D FFT with Wong-Gore modification of the Stokes kernel for the Colorado Experiment: ColFFTWG2020, GFZ Data Services, https://doi.org/10.5880/ISG.2020.004, 2020 b.

Heiskanen, W. A. and Moritz, H.: Physical Geodesy, W.H. Freeman and Co., USA, 364 pp., 1967.

Hodson, S., Jones, S., Collins, S., Genova, F., Harrower, N., Laaksonen, L., Mietchen, D., Petrauskaité, R., and Wittenburg, P.: Turning FAIR into reality: Final Report and Action Plan 
from the European Commission Expert Group on FAIR Data, https://doi.org/10.2777/1524, 2018.

Hwang, C., Hsu, H., Featherstone, W. E., Cheng, C., Yang, M., Huang, W., Wang, C., Huang, J., Chen, K., Huang, C., Chen, H., and $\mathrm{Su}, \mathrm{W} .:$ The gravimetric geoid of Taiwan: TWGEOID18g, GFZ Data Services, https://doi.org/10.5880/ISG.2018.001, 2018a.

Hwang, C., Hsu, H., Featherstone, W. E., Cheng, C., Yang, M., Huang, W., Wang, C., Huang, J., Chen, K., Huang, C., Chen, H., and Su, W.: The hybrid geoid of Taiwan: TWGEOID18h, GFZ Data Services, https://doi.org/10.5880/ISG.2018.002, 2018b.

Ince, E. S., Barthelmes, F., Reißland, S., Elger, K., Förste, C., Flechtner, F., and Schuh, H.: ICGEM - 15 years of successful collection and distribution of global gravitational models, associated services, and future plans, Earth Syst. Sci. Data, 11, 647674, https://doi.org/10.5194/essd-11-647-2019, 2019.

Knudsen, P., Bingham, R. J., Andersen, O., and Rio M. H.: A global mean dynamic topography and ocean circulation estimation using a preliminary GOCE gravity model, J. Geodesy, 85, 861-879, https://doi.org/10.1007/s00190-011-0485-8, 2011.

Kuroishi, Y.: A new geoid model for Japan, JGEOID2000, in: Gravity, Geoid and Geodynamics, edited by: Sideris M. G., International Association of Geodesy Symposia, 123, 329-333, Springer Verlag, https://doi.org/10.1007/978-3-662-04827-6_55, 2000.

Lobianco, M. C. B., Blitzkow, D., and de Matos, A. C. O. C.: The Brazilian gravimetric geoid: MAPGEO2004, GFZ Data Services, https://doi.org/10.5880/ISG.2004.002, 2004.

Longhorn, R.: Geospatial standards, interoperability, metadata semantics and spatial data infrastructure, background paper for NIEeS Workshop on Activating Metadata, Cambridge, UK, 67 July 2005.

Merson, R. and King-Hele, D.: Use of artificial satellites to explore the Earth's gravitational field: Results from Sputnik 2, Nature, 182, 640-641, https://doi.org/10.1038/182640a0, 1958.

Miyahara, B., Kodama, T., and Kuroishi, Y.: Development of new hybrid geoid model for Japan, "GSIGEO2011", Bulletin of the Geographical Information Authority of Japan, 62, 11-20, 2014.

Pail, R., Goiginger, H., Schuh, W.-D., Höck, E., Brockmann, J. M., Fecher, T., Gruber, T., Mayer-Gürr, T., Kusche, J., Jäggi, A., and Rieser, D.: Combined satellite gravity field model GOCO01S derived from GOCE and GRACE, Geophys. Res. Lett., 37, L20314, https://doi.org/10.1029/2010GL044906, 2010.
Pail, R., Bruinsma, S., Migliaccio, F., Förste, C., Goiginger, H., Schuh, W.-D., Höck, E., Reguzzoni, M., Brockmann, J. M., Abrikosov, O., Veicherts, M., Fecher, T., Mayrhofer, R., Krasbutter, I., Sansò, F., and Tscherning, C. C.: First GOCE gravity field models derived by three different approaches, J. Geodesy, 85, 819-843, https://doi.org/10.1007/s00190-011-0467-x, 2011.

Pail, R., Fecher, T., Barnes, D., Factor, J., Holmes, S., Gruber, T., and Zingerle, P.: The experimental gravity field model XGM2016, GFZ Data Services, https://doi.org/10.5880/icgem.2017.003, 2017.

Pavlis, N. K., Holmes, S. A., Kenyon, S. C., and Factor, J. K.: The development and evaluation of the Earth Gravitational Model 2008 (EGM2008), J. Geophys. Res., 117, B04406, https://doi.org/10.1029/2011JB008916, 2012.

Rummel, R. and Teunissen, P.: Height datum definition, height datum connection and the role of the geodetic boundary value problem, B. Geod., 62, 477-498, https://doi.org/10.1007/BF02520239, 1988.

Sansò, F. and Usai, S.: Height datum and local geodetic datum in the theory of geodetic boundary value problems, Allgemeine Vermessungsnachrichten, Wichmann, 8-9, 343-385, 1995.

Sansò, F. and Sideris, M. G.: Geoid Determination: Theory and Methods, Springer Nature, Switzerland, https://doi.org/10.1007/978-3-540-74700-0, 2013.

Sansò, F., Reguzzoni, M., and Barzaghi, R.: Geodetic Heights, Springer Nature, Switzerland, https://doi.org/10.1007/978-3030-10454-2, 2019.

Wilkinson, M. D., Dumontier, M., Aalbersberg, Ij. J., Appleton, G., Axton, M., Baak, A., Blomberg, N., Boiten, J. W., da Silva Santos, L. B., Bourne, P. E., Bouwman, J., Brookes, A. J., Clark, T., Crosas, M., Dillo, I., Dumon, O., Edmunds, S., Evelo, C. T., Finkers, R., Gonzalez-Beltran, A., Gray, A. J. G., Growth, P., Goble, C., Grethe, J. S., Heringa, J., Hoen, P. A. C., Hooft, R., Kuhn, T., Kok, R., Kok, J., Lusher, S. J., Martone, M. E., Mons, A., Packer, A. L., Persson, B., Rocca-Serra, P., Roos, M., van Schaik, R., Sansone, S. A., Schultes, E., Sengstag, T., Slater, T., Strawn, G., Swertz, M. A., Thompson, M., van der Lei, J., van Mulligen, E., Velterop, J., Waagmeester, A., Wittenburg, P., Wolstencroft, K., Zhao, J., and Mons, B.: The FAIR Guiding Principles for scientific data management and stewardship, Sci. Data, 3, 160018 1, https://doi.org/10.1038/sdata.2016.18, 2016. 